STUDI

FRANCESI

\section{Studi Francesi}

Rivista quadrimestrale fondata da Franco Simone

179 (LX | II) | 2016

Varia

\title{
Manuel Norvat, Le chant du divers. Introduction à la philopoétique d'Édouard Glissant
}

\section{Elena Fermi}

\section{(2) OpenEdition}

\section{Journals}

\section{Édition électronique}

URL : http://journals.openedition.org/studifrancesi/4504

DOI : 10.4000/studifrancesi.4504

ISSN : 2427-5856

Éditeur

Rosenberg \& Sellier

\section{Édition imprimée}

Date de publication : 1 septembre 2016

Pagination : 380-381

ISSN : 0039-2944

\section{Référence électronique}

Elena Fermi, « Manuel Norvat, Le chant du divers. Introduction à la philopoétique d'Édouard Glissant », Studi Francesi [En ligne], 179 (LX | II) | 2016, mis en ligne le 01 septembre 2016, consulté le 18 septembre 2020. URL : http://journals.openedition.org/studifrancesi/4504 ; DOI : https://doi.org/ 10.4000/studifrancesi.4504

Ce document a été généré automatiquement le 18 septembre 2020.

\section{(c) $($ ) $\odot$}

Studi Francesi è distribuita con Licenza Creative Commons Attribuzione - Non commerciale - Non opere derivate 4.0 Internazionale. 


\title{
Manuel Norvat, Le chant du divers. Introduction à la philopoétique d'Édouard Glissant
}

\author{
Elena Fermi
}

\section{RÉFÉRENCE}

MANUEL NORVAT, Le chant du divers. Introduction à la philopoétique d'Édouard Glissant, Paris,

L'Harmattan, 2015, 344 pp.

1 Ouvrage issu d'une thèse de doctorat soutenue à la Sorbonne en 2013, cet important essai de Manuel NORVAT parcourt, à travers une analyse approfondie qui ne laisse rien au hasard, l'œuvre poétique et littéraire d'Édouard Glissant en essayant d'en mettre en relief toute la richesse et la complexité que l'auteur rassemble toutefois sous une catégorie commune: celle du «Divers». Divisé en trois grandes parties, «Archéologie du divers glissantien», "Analytique du divers autour de Poèmes complets», «Fragments d'une philopoétique du divers», l'ouvrage tente d'éclaircir, à travers la pensée et l'écriture du poète martiniquais, «en quoi son engagement poétique le conduit à recourir à une philopoétique pour exprimer le Divers du monde» (p. 325). En suivant les études de détail qui ont contribué, au cours des années, à une appréhension immédiate de l'œuvre glissantienne et ont fait grandir l'intérêt des chercheurs vis-à-vis de celle-ci, cette étude tente de dresser, après la mort de l'écrivain en 2011, un bilan critique de sa production.

2 Dans la section intitulée «Archéologie du divers glissantien», Norvat s'interroge sur les influences littéraires et philosophiques qui ont contribué à l'élaboration de la conception glissantienne du Divers. En partant d'une analyse du mot qui en décèle toute la complexité sémantique-Divers se distinguant de Différent mais aussi de Multiple -, le chercheur entreprend un parcours historique afin de saisir l'évolution que cette notion a eue dans l'histoire des idées et de la littérature. Si l'opposition entre 
Relation et Absolu remonte bien aux Présocratiques, il est indéniable que la conception moderne du Divers naît lorsque l'humaniste Montaigne «libère» l'homme de la soumission aux lois divines qui avait caractérisé la mentalité médiévale. Pour ce qui est de l'œuvre de Glissant, Norvat consacre la première section du volume à un parcours autour de l'influence que la lecture de certains écrivains contemporains majeurs a eue sur la pensée et sur l'écriture de l'intellectuel martiniquais, depuis Victor Segalen, en passant par William Faulkner pour en arriver à Saint-John Perse. Point de rencontre des trois écrivains: la participation, à des titres différents, à l'univers de la colonisation et une interrogation qui s'échelonne dans toute leur œuvre sur les enjeux de la relation avec un monde autre que celui du colon européen blanc. Segalen, avec son Essai sur l'exotisme, mais aussi avec Stèles et les Immémoriaux, figure au premier plan des lectures de Glissant qui, au cours des années, lui a souvent rendu hommage en multipliant interventions, commentaires et articles et en contribuant ainsi à la réception de cet écrivain resté longtemps méconnu. La conception du Divers segalenien subit cependant, chez l'écrivain martiniquais, une révision et un dépassement, une reprise et un enrichissement. Segalen «introduit» Glissant surtout parce que la fréquentation de son œuvre pousse l'écrivain martiniquais à aborder le Divers sous le signe de la poésie et à concevoir son expression comme une unité indissoluble de la pensée et de la langue qui l'exprime. Leur dialogue se configure comme un débat incessant qui met en jeu d'autres pensées, d'autres écritures, d'autres esthétiques.

Glissant a consacré à l'œuvre romanesque de William Faulkner plusieurs commentaires, qui ont abouti, en 1996, à la publication de Faulkner, Mississippi, un essai entièrement dédié au romancier américain. L'écrivain martiniquais met en avant, chez ce «colon blanc» qui représenterait son «ennemi» naturel, des thématiques et un renouvellement des modes de l'écriture qui constitueraient une sorte de "préface" à la réflexion littéraire qu'il a entreprise par la suite. Leur œuvre a beaucoup de points communs car elle décrit un univers social colonisé ou issu de la colonisation, en en montrant les contradictions et les enjeux pour cependant les transfigurer et parvenir à leur dépassement.

4 La confrontation avec «l'autre de soi» se poursuit avec Saint-John Perse, lui aussi descendant de colons, qui vit l'écartèlement entre son ancrage antillais et la diversité due à son origine européenne. Glissant entretient avec ce poète un dialogue critique entre louange et dépassement qui l'accompagne tout le long de son œuvre, tout comme il accompagne les principaux acteurs de la créolité. L'œuvre poétique de Perse interroge surtout, philosophiquement, sur la manière de dire le monde après l'avoir pensé, un souci de nominalisation très cher à Glissant qui, à cette fin, a créé beaucoup de néologismes. Tout en gardant chacun son autonomie, les deux poètes ont multiplié les échanges, se sont nourris de lectures mutuelles et ont imprégné leur œuvre d'un même éloge de l'immanence et d'une égale condamnation de la domination.

5 La deuxième section du volume est entièrement consacrée au langage poétique glissantien, à la manière dont il essaie d'exprimer le Divers. Norvat concentre son analyse sur les Poèmes complets qui permettent, selon Bernadette Engel-Roux, de dégager trois périodes majeures qui iraient du chaos primordial à la «Mesure enfin conquise» (p. 145), en passant par le chant imprégné du vers claudélien mais aussi des ressources de Perse et de Senghor. La poésie de Glissant serait donc en constante recréation et, en suivant les variantes successives des Poèmes complets, on pourrait en dessiner le parcours. Avec comme point de départ l'opposition entre l'Un et le Divers, 
développée à maintes reprises par le poète martiniquais, le discours critique de Norvat arrive à mettre en relief quatre significations que Glissant donne à la poésie: dévoiler, c'est-à-dire rechercher les signes, pré-voir, se faire voyant à la manière de Rimbaud, fouiller, aller au plus profond des choses et accorder en trouvant la juste mesure pour s'exprimer.

6 La cohabitation chez Glissant du français et du créole conduit aussi l'auteur du volume à s'interroger sur la vision que le poète a du multilinguisme qui se révèle être un état d'esprit, «une donnée poétique de [sa] conscience (p. 174)». Le dialogue avec Mallarmé et les symbolistes constitue un autre volet de l'analyse: il met en évidence que, malgré les attaches indéniables entre l'œuvre glissantienne et la production mallarméenne, le point de vue de Glissant est tout à fait différent, ancré dans un lieu bien réel, la Caraïbe, et non pas projeté dans des fantasmes abstraits. C'est à partir de cette donnée que Norvat propose un long développement autour de la valeur du paysage dans la pensée de Glissant. Le paysage, martiniquais ou européen, dégagé de tout aura romantique, constitue bien la source première de l'écriture du poète: qu'il soit terrestre ou marin, à dimension humaine ou symbolique, il participe à l'enseignement de la mesure. La géographie glissantienne comporte quelques lieux clé: la clairière, symboliquement reliée au passage de l'opacité au dicible, l'archipel, qui contraste avec l'idée d'enfermement traditionnellement suggérée par le mot île et l'abîme, la profondeur, la faille qui évoque un horizon renversé, un arrière-plan mental et culturel où réel et imaginaire cohabitent sans qu'il soit possible d'établir une véritable ligne de démarcation. Les rapports de Glissant avec l'Histoire font eux aussi l'objet d'un approfondissement dans la deuxième partie du livre. L'image du bateau négrier est à la base du discours poétique de l'écrivain et de l'opposition entre le «nous» des anciens esclaves et le «vous» de leurs maîtres, opposition que Glissant souhaite dépasser au profit d'un chaos-monde qui valorise le Divers des peuples.

7 La troisième section du volume, «Fragments d'une philopoétique du divers», s'attache à analyser le dialogue, qui parcourt toute l'œuvre de Glissant, entre poésie, entendue comme langage littéraire, et philosophie, expression de la pensée, partant du point de vue de la Relation, et du concept de créolisation. Glissant a représenté, au cours de sa vie, un modèle d'engagement intellectuel, en proposant un point de vue personnel sur l'avenir de la Martinique et sa relation à l'histoire coloniale, une perspective qui, loin de céder à un souci de simplification, se veut complexe et multifocale. Le poète veut se faire le porte-parole d'une collectivité; il renonce à revendiquer son rôle auctorial pour devenir le héros du principe cosmique, le Divers, qui lui tient à cœur. Son œuvre résulte en fin de compte impossible à cerner, car il exprime sa conception plurielle par des genres existants ou inventés (poésie, essai, poétrie, etc.), dont la catégorisation pose problème aux chercheurs. Toute tentative de périodisation n'est également qu'un instrument dont on ne peut que mettre en lumière les limites. L'œuvre de Glissant révèle, en effet, toute sa propension à se ramifier et à multiplier les opacités. La question du Divers ne se résume pas chez lui aux rapports philosophiques et littéraires entre unité et diversité mais conduit à s'interroger sur les questions très actuelles de la standardisation et de l'uniformisation sociales. C'est bien dans ce sens qu'elle montre toute sa vivacité et sa postmodernité. La bibliographie glissantienne qui clôt le volume constitue un instrument valable pour approfondir l'étude de l'œuvre de cet intellectuel majeur de la contemporanéité francophone. 